\title{
El pleito Diego Colón-Francisco de Solís: el primer proceso por malos tratos a los indios en La Española (1509) *
}

\author{
Esteban Mira Caballos \\ Universidad de Sevilla
}

El artículo que ahora presentamos constituye un interesante aporte en torno a las relaciones hispano-indias en los primeros años de la colonización. A través de este pleito entre Diego Colón y Francisco de Solís, un miembro de la élite encomendera de Ovando, es posible analizar muchas cuestiones que se han mantenido bastante oscuras hasta nuestros días. Entre éstas podemos citar la visión que tanto vencedores como vencidos tenían de sus respectivos contrarios, mostrándose el indio como un ser con capacidad de juicio, muy lejos de aquellos seres mentirosos y sin razón de que hablaban muchos españoles.

Por lo demás, se establece una periodización de los alzamientos y las huidas quedando bien claro que, tras las guerras de Higuey y Xaragua, el indio no se alzó contra los españoles sino que tan sólo se ausentó y se marchó a los montes. Finalmente, examinamos fenómenos como la evangelización del aborigen, dejando bien sentada la resistencia, o mejor dicho la indiferencia, de éste hacia cualquier tipo de creencias o costumbres que no fuesen las de sus ancestros.

Dada la fecha de 1509 que se maneja, todos estos aportes contribuyen a llenar un vacio importante en torno a las relaciones sociales en los tiempos de la gobernación de frey Nicolás de Ovando.

El documento que ahora presentamos procede del Archivo General de Simancas, de su sección "Diversos de Castilla" 45, n. ${ }^{\circ} 2$. Se trata de cuarenta folios de letra prieta en los que aparecen multitud de informaciones referentes a las relaciones entre conquistadores y conquistados en la etapa final del gobierno de frey Nicolás de Ovando.

* En el transcurso de la publicación de este artículo se ha presentado una comunicación referida a los aspectos lingüísticos de este pleito, aún sin publicar. Se trata de Zamora Salamanca, Francisco José: Contactos lingüísticos entre españoles e indios en un temprano pleito en la Isla Española (año 1509). "Encuentro Internacional sobre los Derechos Humanos en América. Una perspectiva de cinco siglos". Valladolid, 11-16 de mayo de 1992. 
No es el primer pleito importante que aparece en los fondos del Archivo General de Simancas, pues ya el pleito Ovando-Tapia fue descubierto en este archivo y publicado, en 1978, por Emilio Rodríguez Demorizi, ${ }^{1}$ documento que por su temprana fecha y por los ricos datos que ofrece resulta de un gran interés para el estudio de la isla Española en los primeros momentos de la colonización. Otro de estos procesos publicados es el Corvera-Roldán (1511) dado a conocer por fray Vicente Rubio O.P., ${ }^{2}$ también en 1978, y que igualmente constituyó una interesante aportación para la historia de la ciudad de Santo Domingo.

El pleito Colón-Solís, que ahora analizamos y transcribimos parcialmente, aporta igualmente un caudal importante de informaciones, especialmente en lo concerniente al estudio de las relaciones sociales en los orígenes de la colonización española en el Nuevo Mundo.

Diego Colón llegó a Santo Domingo el 9 de julio de $1509^{3}$ con provisiones reales para relevar al comendador mayor en la gobernación de las Indias. Vino con tan amplios poderes como había tenido su antecesor Ovando, es decir: "la gobernación de la isla y oficio de juzgado de ellas, por la parte que a mi toca el tiempo que mi merced y voluntad fuere, con los oficios de justicias y jurisdicción civil y criminal, y alcaldías y alguacilazgos y escribanías de ellas". ${ }^{4}$ El nuevo gobernador no tardó en utilizar plenamente sus facultades, pues en poco más de tres meses de su llegada, inició un pleito contra un poderoso encomendero de la villa de Santiago, sin duda cercano a la facción ovandina, llamado Francisco de Solís, por ocasionar la muerte a dos indios, Francisquito y Guayabax, dando origen al documento que ahora sacamos a la luz. Francisco de Solís era un antiguo poblador de la isla, muy probablemente llegado a América en el cuarto viaje de Cristóbal

1 Rodríguez. Demorizi, Emilio: El pleito Ovando-Tapia (los comienzos de la vida urbana en América). Santo Domingo, 1978.

2 Rubio, fray Vicente: Datos para la historia de los origenes de Santo Domingo (proceso Corvera-Roldán y Pasamonte-Roldán).Santo Domingo, 1978.

3 Arranz Márquez, Luis: 'D. Diego Colón. Madrid, 1982, pág. 108.

4 Ibídem, pág. 101. 
Colón ${ }^{5}$ y ocupaba, en el momento en el que fue acusado, el cargo de alcalde ordinario de la villa de Santiago.

Llama la atención la prontitud con la que el hijo del Descubridor de América llevó a cabo este pleito, aunque pensamos que el descenso de la población aborigen merced al mal tratamiento que le proporcionaban los españoles era ya una realidad conocida en Castilla antes de la llegada del nuevo gobernador, de ahí la rapidez que mostró en emprender el juicio. No olvidemos que ya hacia abril de 1508 se había reunido en Burgos la Junta de procuradores de la isla Española donde se pidieron soluciones para la isla "pues se han apocado tanto (los indios) y se apocan de cada día que, si no se remediara, en pocos días se despoblará de indios". ${ }^{6}$

De esta manera, el litigio comenzó el 20 de octubre de 1509, iniciando los procesos, en calidad de alcalde mayor de la villa de Concepción de la Vega, el licenciado Juan Carrillo que, por las fundadas sospechas de amiguismo con el encausado, fue pronto cesado en favor de Marcos de Aguilar, que fue quien, definitivamente, llevó todo el peso del juicio. Resulta interesante el hecho de que sea el "alcalde mayor de la villa de Concepción y de las otras partes a él cometidas..." 7 el que inicie el pleito y no el alcalde mayor de Santo Domingo, lo cual podía deberse a que era vecino y regidor de la villa de Santiago y se le podía suponer un mejor conocimiento de la situación. Acaso puede ser sintomático, también, de la importancia que llegó a alcanzar este núcleo poblacional de la Vega en los primeros años de la colonización, pues, no en vano, sabemos que frey Nicolás de Ovando sentía una gran predilección por esa villa de Concepción ya que, entre otras cosas, beneficiaba su salud. ${ }^{8}$

Con estos nuevos aires de proteccionismo hacia el aborigen antillano comenzó el gobierno de Diego Colón, aunque, como bien di-

5 El testigo Marcos Pérez de Cáceres, preguntado por cuánto tiempo hacía que vino ante Francisco de Solís, respondió: "que ha más de diez años que vine con él de Castilla". Pleito Diego Colón-Francisco de Solís. Archivo General de Simancas (en adelante AGS), Diversos de Castilla 45, n." 2, fol. 2v. (en adelante se citará como el pleito Colón-Solís).

6 Ibídem, fol. 95.

7 Ibídem, fol. 1.

8 Lamb, Ursula: Frey Nicolás de Ovando. Gohernador de La Española(1501-1509), Madrid, 1956, pág. 154. 
ce Luis Arranz, no pasará de ser una ilusión ya que no hubo solución de continuidad en el sistema de trabajo indígena impuesto por su antecesor frey Nicolás de Ovando. ${ }^{9}$

Los testigos presentados en el pleito se pueden dividir en tres grupos, en función de las respuestas que aportaron al interrogatorio: en primer lugar, un grupo de españoles, todos encomenderos de la villa de Santiago, que eran amigos de Francisco de Solís, y que declararán en su defensa. Entre ellos destacan Pero Sánchez, Juan Barba y Gonzalo de Villegas. Con este último personaje mantuvo una amistad especial pues tenían estancias vecinas en las cuales se intercambiaban indios como mano de obra de una a otra según las necesidades de cada uno. ${ }^{10}$

En segundo lugar, otro grupo de españoles que eran los mozos que trabajaban en la hacienda "La Esperanza", propiedad de Francisco de Solís, que hablarán lógicamente en defensa de su "amo". Sin embargo, había una diferencia vital con los declarantes anteriores y es que aquéllos defendieron a Solís voluntariamente, mientras que éstos lo hicieron bajo fuertes presiones y amenazas. Entre estos testigos tenemos a Marcos de Cáceres y Gonzalo de Niebla, quienes tras ser sometidos a tortura confesaron que sus declaraciones habían sido decididas por Francisco de Solís:

"Y luego, el dicho señor alcalde mayor le mandó volver a poner la tora y dar otro jarrillo de agua y luego el dicho Marcos dijo que le tirasen la tora que él diría la verdad como Dios es verdad fuele tirada la dicha tora y dijo que cuando este testigo fue de aca de decir su dicho el dicho Solís le preguntó que es lo que había jurado y que este testigo se lo dijo y que como había dicho que el dicho Solís le dijo no te acuerdas tu que lo azotó Gonzalo y que con esto que le dijo el dicho Solís por un cabo y Gonzalo por el otro le hicieron decir lo que dijo y varió a la postre en su dicho y que la verdad es que el dicho Solís lo azotó y que murió el dicho indio no el día que lo azotaron ni otro sino otro...". ${ }^{\prime \prime}$

9 Arranz Márquez, Luis: Repartimientos y encomiendas en la Isla Española (el repartimiento de Albuquerque de 1514). Madrid, 1991.

10 El indio Guayabax, por ejemplo, se encontraba trabajando justo antes de su muerte en la hacienda de Gonzalo de Villegas, pues Francisco de Solís se lo había prestado. Pleito Colón-Solís, fol. 28 y ss.

11 Pleito Colón-Solís, fol. 10v. 
En tercer lugar, un grupo de españoles que están a medio camino entre los testigos anteriores y los testigos indios. Son españoles que nada tienen que ver con la élite encomendera, siendo exclusivamente testigos presenciales que se limitarán a contar los hechos tal y como ocurrieron, aunque restándole alguna dureza y dramatismo a la situación. Entre ellos estaban Cristóbal de Valdovinos, que fue el que trajo al indio Francisquito del Marien, y Francisco Chocarrero, una especie de "bufón" que recorría las estancias contando "chocarrerías" a cambio de manutención y que se encontraba en la hacienda "La Esperanza" en el momento de acontecer los hechos. Con todo, pese a que intentaron restar dureza a lo ocurrido, Solís en la probanza que realizó en su defensa, los desacreditó como testigos calificándolos de "perjuros", "viles" y de "poca opinión" pues tenía la intención de desmentir todo lo que se le imputaba. ${ }^{12}$

Finalmente, y como cuarto grupo, aparecen como declarantes los indios naborías de Francisco de Solís, que fueron testigos presenciales, y una india llamada Catalina, que era esclava del ya citado encomendero Gonzalo de Villegas. En el pleito puede verse cómo todos los indios fueron uniformes en sus declaraciones al afirmar unánimemente que el indio Guayabax murió de los azotes recibidos. Como ejemplo de lo alegado por los indígenas sirva la declaración del indio Miguelito, referente a la muerte de Francisquito:

"Dijo el dicho intérprete que el dicho indio Miguelico decía que vio que el dicho Solís hizo atar las manos altas al dicho Francisquito a la dicha tiranta y los pies que llegaban a mala pena al suelo con un hizo y que Francisco Chocarrero, por mandato del dicho Solís, con un cordel de la cincha del caballo, le dio obra de cuarenta azotes y que el dicho Solís tomo el azote de la mano al dicho Francisco Chocarrero y que le dio él mismo Solís otros muchos azotes diciéndole a cada azote que le daba "axura higuerito, axura señor porque vos acordéis" y que cuando el dicho Solís le comenzó a dar al dicho indio que ya el dicho indio tenía corriendo la sangre las espaldas... Dijo el dicho intérprete que decía el dicho indio Miguelito que el dicho Francisquito murió de los azotes, a lo que él cree porque venía sano y bueno y comía y bebía". ${ }^{13}$

12 Ibídem, fol. 28 y ss.

13 Ibídem, fol. 5-5v. 
La sentencia dictada por el alcalde mayor de La Española, el 15 de agosto de 1510, y notificada a Solís tres días después, lo condenó al destierro de la villa de Santiago, ${ }^{14}$ dictamen que fue, sin embargo, apelado al Consejo, presentándose en Sevilla el 26 de marzo de 1511. Del resultado de esta apelación no tenemos ninguna información, aunque en principio nos llama enormemente la atención el hecho de que se recurriera, ya que en los casos de indios los pleitos solían sentenciarse en la misma ciudad de Santo Domingo. Así, en un pleito de indios transcurrido entre 1529 y 1531 los testigos van a afirmar: "que los tales pleitos de indios no se acostumbran a ir a Castilla sino que fenecen y se acaban y así el proceso entero y ésto es uso y costumbre general en esta isla usado y guardado...". 15

No obstante, creemos que la sentencia fue ratificada por el Consejo pues en el repartimiento de Albuquerque de 1514 aparece Francisco de Solís no como vecino de Santiago sino como de Santo Domingo, con una encomienda de 34 indios de repartimiento y naborías. ${ }^{16}$

\section{Las relaciones hispano-indias en torno a 1509}

\section{Vencedores $y$ vencidos}

En el documento objeto del presente estudio se pueden analizar perfectamente dos puntos de vista antagónicos, es decir: la visión que tanto vencedores como vencidos tenían de sus contrarios ya que, por primera vez, van a aparecer testigos indios y españoles en una misma causa.

La visión que el español tiene del indio queda bien patente en las declaraciones que hacen los testigos que utiliza Solís en su defensa. Se les considera ante todo personas, aunque de poco juicio y

14 Ibídem, fol. 39.

15 Archivo General de Indias (en adelante AGI), Justicia 6, n." 4. Pleito entre Diego Méndez y Juan Roldán. Interrogatorio de Diego Méndez, 1529-1534.

16 Arranz, Repartimientos, pág. 535. 
entendimiento. Es, pues, una convicción ontológica de la inferioridad del indio con respecto al "cristiano", sutilmente utilizada por el reo Francisco de Solís para invalidar las acusaciones que sobre él vertían, obviamente, los testigos indios. Así, la pregunta octava de su defensa va a ir al fondo de esta cuestión, al poner en entredicho la facultad de los indios para ser presentados por testigos en un juicio. Textualmente dice así:

"Item, si saben y creen que todos los indios generalmente son hombres de poca conciencia, que no temen a Dios ni cumplen sus mandamientos, ni saben que daño se recrece de jurar falso y no decir verdad... Y en poco temor y dádivas dicen lo que es y lo que no es, por tales son habidos y tenidos comúnmente reputados".

Todos los testigos presentados por Solís respondieron afirmativamente a esta pregunta, pues habían sido especialmente seleccionados por el propio Solís. Así, por ejemplo, Juan de Aguirre respondió: "Que es verdad todo lo contenido en la dicha pregunta porque así es notorio y por tal este testigo lo tiene, y tienen muchas tachas allende de las contenidas en estas partes que son largas de decir". ${ }^{18}$ No obstante, sabemos, por otras muchas referencias documentales, ${ }^{19}$ que una gran mayoría de los españoles así los consideraban, es decir, como hombres de poca conciencia, no cristianos $\mathrm{y}$ volubles en sus pensamientos.

Por tanto, hombres racionales pero inferiores, lo cual ha sido siempre una constante en todas aquellas culturas que con un estadio más avanzado entraban en contacto con otras culturas inferiores. Ya los griegos, 1300 años antes, habían dicho que "lo griego era el crisol superior de un mundo diverso". Los españoles se planteaban ahora la visión desde la misma óptica que aquellos griegos:

17 Pregunta octava del interrogatorio presentado para su defensa por Francisco de Solís. Pleito Colón-Solís, fols. 28v.-29.

18 Ibídem, fol. 30v.

19 Interrogatorio de los Jerónimos, 1517. AGI, Indiferente General 1624, r. 3, n." I. Reproducido parcialmente en Codoin, Serie 1. a, t. I, págs. 201-229. Las respuestas de Vázquez de Ayllón y de fray Bernardo de Santo Domingo en Giménez. Fernández, Manuel: El plan Cisneros-Las Casas para la reformación de las Indias. Madrid, 1984, págs. 573-596. Y de forma casi íntegra en Rodríguez Demorizi, Emilio: Los dominicos y la encomienda de indios en la isla Española. Santo Domingo, 1971, págs. 273-354. 
"Los mejores somos nosotros y lo nuestro, puesto que somos los únicos que nos planteamos tales cuestiones". ${ }^{20}$

Mucho más interesante y novedosa resulta ser la visión que el indio tenía del castellano. Ante todo, muestra un cierto rechazo hacia una parte importante de la cultura hispana, pese a que los testigos indios son naborías "muy ladinos", pues, según se dijo en el pleito, "así pareció claramente por los dichos Sebastianico, Mencía y Catalina porque lo mismo dijeron en lengua castellana, que son ladinos" ${ }^{21}$ no aceptando la religión cristiana - aspecto que analizaremos con detenimiento más adelante - y continuando con muchos de sus comportamientos tradicionales.

Todos los testigos españoles declararon que el indio sentía un gran odio hacia el español. Así, uno de éstos decía: "que claro está que quieren mal a los cristianos y que los querrían ver muertos porque los castigan y apremian, lo cual es así público y notorio en esta isla". ${ }^{22}$ Incluso se cita a un indio, llamado Escobar, que fue mandado azotar por Francisco de Solís "porque tomó un cuchillo para matar (a) un cristiano". ${ }^{23}$ Igualmente, el español Rodrigo de Manzorro, en su declaración afirmó de los indios: "que sabe que son personas de muy poco juicio y saber y que no saben que cosa es conciencia ni jurar y que quieren mal a los cristianos y aun a quien los trata bien, la mayor parte de ellos". ${ }^{24}$ Por su parte, el testigo Pedro Hernández Herrador declaró a la misma pregunta lo siguiente:

"Que cree todo lo que en la dicha pregunta se contiene, preguntado que por qué lo cree dijo que porque algunas veces en casa del Comendador Mayor ha habido Alonso de Cáceres, indio, que es lengua bien entendido estar borracho con hierbas u otros muchos indios decir mentiras y que claro está que quieren mal a los cristianos y que los querrían ver muertos porque los castigan y apremian lo cual es así público y notorio en esta isla...." ${ }^{25}$

20 García, Alejandro: Civilización y salvajismo en la colonización del Nuevo Mundo. Un ensayo sobre la penetración de la cultura europea. Madrid, 1986, pág. 54.

21 Pleito Colón-Solís, fol. $21 \mathrm{v}$.

22 Ibídem, fol. 34.

23 Ibídem, fol. 30.

24 Ibídem, fols. 31-3Iv'

25 Ibídem, fol. 34. 
No obstante, pensamos que esta última afirmación puede tratarse de una acusación justificada tan sólo en el intento de desacreditar a los indios como testigos en un juicio. De hecho, no conocemos otros pleitos en la isla Española en los que participen indios bajo juramento, lo que quizá indique que quedó prohibido. Esto además se puede confirmar por un cargo que se le hizo al licenciado Altamirano, gobernador de la isla Fernandina, en su juicio de residencia:

"Item, se le hace cargo que estando proveído y no usado en estas partes que ningún indio se le tome juramento en ningunas causas por ser los tales indios incapaces y no saber que cosa es juramento ni en que consiste el odio se les tomó juramento a indios bozales contra un Antonio de Valladolid". ${ }^{26}$

Por lo demás, y contrariamente a lo que habían dicho los españoles, los indios en sus respuestas al interrogatorio del alcalde mayor, a la par que declararon sin miedo todo lo sucedido con los indios azotados, afirmaron que no querían mal a los españoles, sólo deseaban que se hiciese justicia en ese caso concreto. Igualmente, sabemos que estos indios eran incluso capaces de hacer juicios de valor y distinguir el comportamiento de unos españoles con respecto a otros. Así, resulta muy significativo lo expuesto por el indio Sebastianico sobre Francisco de Solís cuando lo denomina, en su declaración, con el apodo de Francisco "el loco".

El indígena aparece, pues, como un ser racional que es capaz de aprender lo que le interesa y que tiene conciencia individual, de sentirse diferente de lo castellano y por extensión de lo cristiano. De manera que si bien es cierto que no se pudo desarrollar entre los indios una conciencia de grupo debido, entre otras causas, a los repartimientos indiscriminados que se hicieron sin respetar tribus ni clanes, no es menos cierto que sí hubo una conciencia a nivel de individuo de sentirse diferente e incluso de discernir entre lo bueno y lo malo de los nuevos pobladores.

26 Juicio de residencia al licenciado Altamirano, gobernador de la isla Fernandina. Santiago, 1525. AGI, Justicia 49, n.” 2, r. 1. 


\section{El sistema laboral indígena}

Toda la ordenación del trabajo indígena que llevaron a cabo los españoles se articuló a través de la figura del cacique, que se convirtió desde los primeros momentos en el instrumento básico de control sobre los indios. Esta circunstancia fue muy pronto comprendida por las autoridades españolas pues según una carta que, en 1516, dirigieron los dominicos de La Española al Señor de Chiévres le decían que "para servirse de los indios (los españoles) prendían los caciques porque ha sido gente que tenían mucho amor a sus señores y éranles muy leales de tal manera que por tenerlos seguros que no se fuesen bastaba tenerles preso a su señor....". ${ }^{27}$

Todavía en un parecer del Consejo de Indias de 1533 se ordenaba claramente que no se le quitase superioridad a los caciques "porque sino se perderían todos los indios y no querrían servir". ${ }^{28}$ Esta función del cacique queda bien patente en el pleito que analizamos, pues cuando el alguacil del campo salió a buscar a Guayabax tan sólo necesitó acudir al cacique Nibrón para que lo trajese sin dilación, cosa que hizo eficazmente. ${ }^{29}$

Sin embargo, queda mucho mejor definido en este documento el indio naboría pues, excepto Mencía, que era esclava, el resto de los indios que participan en el pleito son naborías. Este término designa a un indio con un status laboral y social distinto al del repartimiento. Más concretamente, y según se define en la documentación de la época, eran aquellos "que servían contra su voluntad, casi como esclavos, aunque no se vendían y es de esta manera que los tenían depositados personas para servirse de ellos en las minas y en sus haciendas y si se querían ir a un cabo no podían porque se llamaban naborías...". ${ }^{30}$

27 Carta de los dominicos al Señor de Chiévres, Santo Domingo, 4 de junio de 1516. Marte, Roberto: Santo Domingo en los manuscritos de Juan Bautista Muñoz. Santo Domingo, 1981, págs. 160-180. bre de 1533

28 AGI, Patronato 170, r. 4l. Parecer del Consejo de Indias, Madrid, 8 de diciem-

29 Pleito Colón-Solís, fol. 15v.

30 AGI, Patronato 23I, n." I, r. 4. Información sobre la libertad de los indios. Declaración del testigo Luis de Morales, 23 de junio de 1543. 
Conocemos dos tipos diferentes de naborías: los que se denominaban de casa, y los de granjerías y minas. Ambas situaciones están perfectamente definidas en el pleito. Entre los primeros, es decir, entre los de casa, aparece tan sólo Catalina, que era la cocinera de Francisco de Solís, o la mayordoma, según la denominó uno de los testigos españoles. ${ }^{31}$ Esta india trabajaba diariamente, y a lo largo de toda su vida, de manera ininterrumpida, en casa de Francisco de Solís, motivo por el cual se encontraba totalmente ladina. Ignoramos, sin embargo, si esta india dormía en la estancia "La Esperanza" en una hamaca que, según se menciona, había en la cocina, o si durante la noche iba a dormir con el resto de los indios naborías de la hacienda al bohío del capitán. En cualquier caso, la vida de estas naborías de casa era sustancialmente más favorable que la del resto de los indios, haciendo de cocineras, "mayordomas", curanderas $y$, en muchos casos, de concubinas de los españoles a los que estaban encomendadas.

Los otros indios naborías, es decir, los de granjerías y minas, trabajaban en las minas durante la demora con los demás indios de repartimiento, ejerciendo el otro tercio del año en la labor de la hacienda de Francisco de Solís, mientras que los indios de repartimiento marchaban a holgar a sus conucos o pequeñas parcelas de cultivo. Eran usados prácticamente como esclavos, pudiéndose prestar y alquilar sin ser un hecho punible, aunque sí estaba castigada su venta.

En este sentido, Gonzalo de Villegas declaró que los indios de Solís los trajo él a su hacienda porque éste se los prestó para que "los trajese en su conuco hasta que se hubiesen de ir a las minas". ${ }^{32}$ El trato debió ser más duro, incluso, que el de cualquier esclavo, ya que éstos, al costar dinero, suponían una inversión en mano de obra que había que conservar, mientras que los indios eran explotados al límite pues los encomenderos sabían "que se los cambiaban cada vez que estos morían". ${ }^{33}$ Hasta tal punto se explotaba a estos indios que ni siquiera las dolencias eran excusa suficiente para

31 Declaración de Francisco de Burgos. Pleito Colón-Solís, fol. 15.

32 Pleito Colón-Solís, fol. 23v.

33 AGI, Justicia 42, Pieza 1. Declaración que hizo Francisco de Monroy a la octaba pregunta en el Juicio de Residencia de los jueces de apelación. 1516. 
dejar, durante unos días, el trabajo. Así, por ejemplo, el indio Guayabax, tras ser azotado y pese a tener la espalda sangrante y padecer calenturas, fue obligado a ir al conuco de Gonzalo de Villegas "y adolesció en el dicho conuco y le dieron calenturas y cada noche se venía desde el conuco a dormir a casa" hasta que murió. ${ }^{34}$

Pese a la comunicación continua con los españoles la "ladinización" sólo implicaba el conocimiento de la lengua española y la habilidad para desarrollar eficazmente su trabajo en las minas y labrantío, pero no afectando a otras cuestiones de su cultura. En este sentido, sabemos que no residían bajo el mismo techo que los castellanos sino en unos bohíos que había al lado de las estancias de los españoles, manteniendo allí parte de su cultura tradicional, sus comidas, sus ritos y sus tradicionales métodos curativos. ${ }^{35}$

\section{Las huidas indígenas}

En el documento que ahora analizamos se distingue perfectamente el concepto de indio huido, que es al que se alude, y no al otro término bien distinto de alzamiento. El primer término se refiere tan sólo a un rechazo del indio al servicio y a la comunicación con el español, mientras que el segundo, implica una consciencia de ataque hacia todos los intereses españoles. El alzamiento, por su parte, estaba castigado con la esclavitud, mientras que el ausentamiento se penalizaba con un castigo consistente en unos moderados azotes con vistas al escarmiento.

El comendador mayor frey Nicolás de Ovando había dejado la tierra perfectamente pacificada, de manera que después de las matanzas de Xaragua e Higuey, los indios se ausentaban de sus encomenderos pero, desde luego, no había una intención de ataque hacia ellos. El acusado, Francisco de Solís, reconoció haber azotado a lo largo de su ejercicio como alcalde ordinario a muchos indios que se ausentaban por no servir a los españoles. Así, afirmó haber azo-

34 Declaración de Gơnzalo de Villegas. Pleito Colón-Solís, fols. 23v-24.

35 Véase, por ejemplo, lo que se dice en el Pleito Colón-Solís, fol. Iv. 
tado al indio Guayabax "porque era bellaco, que no quería reposar en mi casa, ni en las minas y se huía y se ausentaba". ${ }^{36}$ Está claro que el castigo para estos indios no era la esclavitud sino tan sólo un escarmiento, ordenándose lo primero tan sólo en el caso de que el indio ausentado ya fuese esclavo previamente. Este tono van a tener las Instrucciones a Nicolás de Ovando, de 1508, en las que se autoriza a que vuelvan a la servidumbre aquellos indios que se hubiesen esclavizado en las primeras guerras de La Española y que se habían ausentado luego a los montes, para que no sirvieran de ejemplo a los otros indígenas. ${ }^{37}$

En caso de huidas era el alcalde ordinario quien entendía en primera instancia tanto para los asuntos de españoles como de los indios. Este ordenaba su búsqueda y traído a su presencia decidía el castigo exacto en función de las circunstancias de su fuga o de su posible reincidencia. Creemos que en este territorio había cierta legislación, posiblemente oral y consuetudinaria, sobre el castigo que los alcaldes ordinarios debían dar a los indios, pues si nos atenemos a lo expuesto por Solís vemos cómo su intención no fue otra sino la de castigarlos "como se suele y acostumbra a hacer en esta isla, a los indios que no quieren servir a las personas a quien se encomiendan". ${ }^{38}$

Por otro lado, hemos de reseñar la ausencia de la figura del visitador, que no se menciona en ningún momento del pleito, ni existía además en la villa de Santiago para estas fechas. Se trata, sin duda, de una cuestión importante ya que hasta ahora se creía, por referencias del padre Las Casas, que esta institución había sido creada por el gobernador frey Nicolás de Ovando, punto que era aceptado, sin discusión alguna, por la historiografía reciente. ${ }^{39}$ Es

36 Ibídem, fol. 19v.

37 AGI, Indiferente General 1961, I. 1, fols. 31-36v. Instrucciones a frey Nicolás de Ovando, Burgos 30 de abril de 1508.

38 Pleito Colón-Solís, fols. 19-19v.

39 El padre Las Casas afirmó que el comendador mayor creó la figura del visitador en cada una de las villas de La Española: "Un vecino, el más honrado caballero del pueblo, al cual puso nombre visitador, y a quien por sólo el oficio, como por salario, sin el repartimiento que le había cabido de indios, le daba otros cien indios, que como los otros le sirviese". Las Casas, Bartolomé de: Historia de las Indias, Madrid, 1957, t. II, pág. 39. Citado también por Arranz: Repartimientos, pág. 102. 
más, en relación a esto, el testimonio del testigo Juan Carrillo Mexía nos confirma esta situación al responder en una de las preguntas: "que el dicho Francisco de Solís siendo alcalde azotaba algunos indios, como juez", ${ }^{40}$ todo lo cual nos hace pensar que los visitadores durante la época del gobernador Ovando, sólo tuvieron una existencia ocasional. Esto, además, es fácilmente deducible de las Leyes de Burgos, expedidas como es bien sabido en 1512, en las cuales se dedicaban varios capítulos a este cargo de visitador con la intención de regular, de una vez por todas, su actividad. ${ }^{41}$ Por todo ello, pensamos que el visitador comenzó a tener alguna importancia desde los años del gobierno de Diego Colón, y que será ya a partir de 1514, cuando se institucionalice tal figura de una manera permanente en La Española.

Los indios ausentados eran buscados por los alguaciles de campo que había en cada villa de españoles. Se confirma, pues, con el estudio de este pleito otro dato del que sólo se tenía conocimiento, también a través del padre Las Casas, cuando habló de "ciertos alguaciles de campo que los iban a montear y traerlos (a los indios)". ${ }^{42}$ Así, nos aparece la figura de Gaspar Briceño, que ejerció este oficio en la villa de Santiago y cuya misión era traer a los indios ausentados que el alcalde ordinario le señalaba buscar. Por tanto, los alguaciles del campo existieron desde los primeros tiempos de la colonización, con la función específica de traer indios que se escapaban a los montes, misión que más adelante se adaptaría a las nuevas circunstancias al encargársele la traída de negros alzados. ${ }^{43}$

En resumen, podemos decir que la huida fue un fenómeno común en la época del gobernador Ovando, siendo el castigo común un azote ejemplar y no la esclavitud, como bien queda de manifiesto, con lo anteriormente expuesto.

40 Pleito Colón-Solís, fols. 33-33v.

41 Los capítulos en los que se hace referencia al visitador en las Leyes de Burgos son el 24 y del 29 al 33. El texto que hemos utilizado ha sido el que ofrece Muro Orejón, Antonio: Ordenanzas reales sobre los indios. (Las Leyes de 15/2-1513), en "Anuario de Estudios Americanos", Vol. XIII, Sevilla, 1956, págs. 417-471.

42 Citado por Arranz: Repartimientos, nota 165.

43 AGI, Justicia 61, n.' I, fol. 2600. Juicio de Residencia del licenciado Alonso de Fuenmayor y los oidores de la Audiencia de Santo Domingo, 1541. 


\section{El proceso de aculturación en la época de Ovando}

El indio antillano asimiló con cierta rapidez una parte de la cultura española: en concreto la material y tecnológica. Ya en un temprano documento de 1503 se decía que había algunos indios que utilizaban a los perros para cazar. ${ }^{44}$ En otro documento, en este caso referido a los aborígenes de la isla Fernandina, aunque perfectamente extrapolable a los de La Española, se hacía referencia a los indios naborías, que pese a estar 30 ó 40 años en casa de los españoles, no rezaban el Ave María. Sin embargo, "todos los más (indios) andan a caballo y tienen caballos y algunos de ellos tres o cuatro caballos, y los días que andan a montear se les da caballos a algunos de ellos en que traigan la carne, y en sus caballos de ellos mismos o de sus amos la traen...". ${ }^{45}$ De manera que la cultura material se aceptó sin problemas, siendo este pleito una muestra más de esta aceptación al comprobar cómo cuando Francisco de Solís ordenó enterrar al indio Francisquito los indios cogieron una azada de metal para cavar su tumba, ${ }^{46}$ signo de estar aceptando un elemento de la tecnología hispana.

En cuanto a los aspectos religiosos, y según se infiere en el pleito Colón-Solís, la evangelización del indio en la época del gobernador Ovando, dejó mucho que desear. Es conocida una cédula del rey a Diego Colón pidiéndole que procurase la evangelización del indio de la isla de Santiago para que no ocurriese lo que en La Española "que no tienen más de cristianos sino el nombre, salvo los muchachos que crían los frailes que aquellos, dicen, que los hacen bien...". ${ }^{47}$ Realmente el indio de La Española nunca abandonó sus ancestrales ideas religiosas, pues los documentos de la década de los cuarenta son tan pesimistas en este sentido como los de los pri-

44 AGI, Indiferente General 418, I. I, fol. 119v. Real cédula a frey Nicolás de Ovando, Segovia, 27 de noviembre de 1503.

45 AGI, Justicia 69, n." I, fols. 51 y 231 v. Residencia al gobernador de Fernandina Juanes Dávila, 1545.

46 Pleito Colón-Solís, fol. 3.

$47 \mathrm{AGI}$, Indiferente General, 418, I. III, fols. 77v-82. Respuesta al almirante Diego Colón, Sevilla, 6 de junio de 1511 . 
meros años de la decimosexta centuria. ${ }^{48}$ Parece claro, en consecuencia, que los bautizos que hicieron el padre Boil y los demás frailes los recibieron los indios "más por lo que les mandaban sus amos, que movidos a devoción". ${ }^{49}$

Notamos, pues, en los indios una gran resistencia al cambio ideológico y en especial religioso, sin duda porque estaban plenamente convencidos de que eran sus dioses tradicionales sus auténticos protectores y los que satisfacían sus necesidades psicológicas. ${ }^{50}$ Estos, pronto identificaron los símbolos cristianos con la sumisión a la opresión española, como parece desprenderse de una carta de los frailes de La Española al señor de Chièvres en la que reconocían ya en 1518: "que entre los indios ya había opinión que los frailes no iban allá sino a amansarlos para que los cristianos los tomasen para matarlos". ${ }^{51}$

De hecho, en el pleito que analizamos podemos comprobar en general cómo todos los castellanos declararon que, pese a ser ladinos los indios naborías presentados como testigos, no creían en Dios. Esta idea se puede observar en declaraciones como la que hizo el testigo Miguel de la Casa a la octava pregunta de la probanza de Solís:

"Que (los) tiene por hombres de poca conciencia y que ni temen a Dios, ni saben que cosa es ni en que se perjuran o dañan sus conciencias, preguntado por qué los tiene por tales dijo que porque algunas veces ha oído decir a indios que creen en cemíes y que no quieren ser cristianos ni saben que son los mandamientos y que este testigo y que este testigo ( juramento ni aun sin él porque algunas veces los ha visto contradecirse y no saber si se contradicen ni si no". ${ }^{2}$

48 Véase, por ejemplo, real cédula al presidente y oidores de la Audiencia de Santo Domingo, Toledo, 25 de octubre de 1538. AGI, Audiencia de Santo Domingo 868, I. I, fol. 149. pág. 33.

49 Mendieta, fray Gerónimo de: Historia eclesiástica Indiana. México, 1980, cap. VI,

50 Nishert, Robert y otros: Cambio social. Madrid, 1988, pág. 54.

51 Carta de los dominicos de La Española al Señor de Chièvres, Santo Domingo, 4 de junio de 1518. Citada por fray Juan Manuel Pérez, O. P.: Estos ¿no son hombres?. Santo Domingo, 1984, pág. 15.

52 Respuesta del testigo Miguel de la Casa. Pleito Colón-Solís, fol. 33. 
Es evidente el rechazo de los indios no sólo hacia el cristianismo sino hacia todos los cristianos. No es que no alcanzasen a creer en los elevados conceptos católicos, sino que "no querían ser cristianos", ni mostraban interés alguno por aprender las bases teológicas de la fe católica.

Un aspecto muy sintomático de todo lo que estamos diciendo lo constituye el enterramiento de los indios azotados Francisquito y Guayabax. En el caso del primero, se mandó enterrar en el campo, aunque desde luego se hizo sin ningún tipo de liturgia católica, pues fue sacado del bohío de los indios y llevado a sepultar sin la presencia de fraile alguno. Esta circunstancia no debe, sin embargo, sorprendernos demasiado pues todavía en 1514 se lamentaba el rey de que los indios que fallecían en las minas "los entierran en el campo como a infieles...", ${ }^{53}$ proponiendo al respecto que se tuviesen libros de nacimientos y defunciones para impedir, en la medida de lo posible, estas situaciones.

El caso del indio Guayabax se muestra totalmente diferente ya que, pese a que fue mandado sepultar, los testigos declararon unánimemente que no lo llegaron a enterrar sino que simplemente "lo echaron en la sabana". ${ }^{54}$ Resulta interesante esta cuestión, pues aparece esta tendencia aborigen a no enterrar a sus muertos como era su costumbre, pese a que así fue ordenado por Francisco de Solís. Es evidente, por tanto, que esta circunstancia no puede ser atribuida a un acto concreto sino, más bien, a una práctica usual entre los indios desde la época prehispánica.

Hay que poner, pues, todo esto en relación con el bajo número de enterramientos indígenas que se han encontrado en La Española, lo que ha hecho sospechar a los antropólogos e historiadores que tan sólo se enterraría a los caciques y gentes principales. ${ }^{55} \mathrm{Ya}$

53 AGI, Indiferente General 419, Lib. V, fols. 37-37v. Real cédula a Diego Colón y a los jueces de apelación de la isla Española, Valladolid, 27 de septiembre de 1514.

54 Véase, por ejemplo, la declaración de la india Mencía. Pleito Colón-Solís, fols. 16-16v.

55 Cassá, Roberto: Los taínos de la Española. Santo Domingo, 1990 (3.“ ed.), páginas $180-181$. 
el padre Las Casas en su Historia de las Indias decía que era costumbre de los indios abandonar a los viejos y enfermos en los bosques con pequeñas raciones de agua y comida. ${ }^{56}$ También Mártir de Anglería se hace eco de esta práctica entre otros indios isleños que puede servir para reforzar la tesis que planteamos. Concretamente decía lo siguiente:

"también de los de Cariari conservan, desecándolos en parrillas, los cadáveres de sus próceres y sus padres, envolviéndolos en hojas de árboles; para el pueblo los bosques y las selvas les sirven de sepulcro". 57

También en el aspecto medicinal, que ha estado en todas las culturas primitivas muy ligado al mundo mágico-religioso, notamos un continuismo en la cultura indígena. Sin duda, los curanderos taínos rivalizaban, en los primeros tiempos, con los modestos barberos y médicos españoles cuyos conocimientos eran muy restringidos y sus remedios se limitaban a realizar sangrías y preparar algún emplasto de hierbas, curando tan sólo las heridas de superficie. De manera que, en el pleito se dice que cuando el indio Francisquito agonizaba, en un último esfuerzo por salvarlo, lo llevaron los indios al bohío del capitán "para que lo curasen mejor". ${ }^{58}$ Desgraciadamente, en este texto no se especifican los sistemas médicos que empleaban los curanderos indios.

56 Ibídem, pág. 181.

57 Mártir de Anglería, Pedro: Décadas del Nuevo Mundo. Madrid, 1989, década III, cap. IV, pág. 191. También transcrito por Gil, Juan y Consuelo Varela: Cartas de particulares a Colón y relaciones coetáneas. Madrid, 1984, págs. 116-117. Por su parte, Fernández de Oviedo decía lo siguiente de los enterramientos: "Diversas maneras de enterrar los difuntos entre sí tienen; unos los entierran con agua en las sepulturas, poniéndoles en la cabecera mucha comida, creyendo que para el camino de la otra vida o en ella de aquello se mantengan; lloro ninguno ni sentimiento hacen por los que mueren. Otros tienen queste uso, que cuando les parece que el enfermo está cercano a la muerte, sus parientes más cercanos lo llevan en una hamaca al monte, y allí, colgada la hamaca de dos árboles, un día entero les hacen muchos bailes y cantos, y viniendo la noche, pónenle a la cabecera agua y de comer cuanto le podrá bastar por tres o cuatro días, y dejanló allí, vansé y nunca más lo visitan...". Fernández de Oviedo, Gonzalo: Historia general y natural de las Indias, México, 1951, t. II, I. I, cap. CLXIV, pág. 122.

58 Pleito Colón Solís, fol. Iv. 
Parece evidente, pues, que los indios en la primera década del siglo XVI, habían asimilado la parte de la cultura que les interesaba, que eran capaces de asimilar también la religión, pero que sus mecanismos culturales de defensa les impidieron aceptar la nueva creencia y abandonar sus ritos tradicionales, produciéndose así el sincretismo religioso que caracterizó a las culturas indígenas del Nuevo Mundo durante la colonización española. 


\title{
Apéndice
}

\author{
PROCESO DE INDIOS ENTRE FRANCISCO DE SOLÍS \\ Y LA JUSTICIA DE LA ESPAÑOLA SOBRE MALOS TRATOS \\ A LOS INDIOS. EMPIEZA EN LA VILLA DE SANTIAGO \\ EL 20 DE OCTUBRE DE 1509 Y SE PRESENTÓ \\ EN LA CIUDAD DE SEVILLA EL 26 DE MARZO DE 1511 \\ APELADO POR EL DICHO FRANCISCO SOLÍS
}

-F. I-En la villa de Santiago, veinte días del mes de octubre año del nacimiento de Nuestro Señor Jesucristo de mil y quinientos y nueve años, el muy virtuoso señor el licenciado Juan Carrillo, alcalde mayor de la villa de la Concepción y de las otras partes a él cometidas por el Ilustre y muy Magnífico señor don Diego Colón almirante, visorrey y gobernador de las dichas Islas y Tierra Firme del mar Océano por sus Altezas el señor alcalde mayor mandó hacer cierta información de ciertos indios que dicen que mató Francisco de Solís, alcalde ordinario de la dicha villa de Santiago, y por ante Cristóbal de la Torre, escribano público de la dicha villa. Se recibió juramento de los testigos que se siguen:

En este día juró Marcos de Cáceres y siendo presentado por el dicho señor alcalde mayor dijo que la demora pasada le trajeron un indio al dicho Francisco de Solís que se llamaba Gasparico a la estancia de la Esperanza, que andaba ausentado, y que lo trajo Cristóbal, criado del dicho Solís, y otro indio que se llamaba Zoquillo que también andaba ausentado y que el dicho Solís lo hizo atar y le dijo que "axura el higuerito" I y que por qué se había ido y nota y que venía el dicho indio Gasparico mal y que con un hizo ${ }^{2}$ le dio obra de ocho o diez azotes y que cree que antes y por látigo, que no hizo, con que le dio y que el dicho Francisco de Solís le $-f$. $l v$-dio los dichos azotes y que estaban presentes este que depone y Cristóbal que lo había traído y Francisco el Chocarrero y que podría ser hora de vísperas cuando lo azotó y que después el dicho indio

1 Pese a que hemos utilizado varios vocabularios indígenas, no hemos podido averiguar el significado de tales palabras. Aunque una interpretación podía ser la siguiente: "Axura" podría ser adjura, e "Higuerito" el nombre indígena de Francisquito, por lo que podrían entenderse que mientras le pegaba le decía "adjura higuerito y el indio respondía "adjuro señor".

2 El término "Hizo" proviene de hiza (Sapium lateliflorum), que es un árbol leñoso, originario de ciertas regiones americanas. En sentido figurado, puede interpretarse como palo o rama recia. 
azotado se fue a la cocina y el dicho a comer pan y carne y que este testigo lo dio a una india, que se llama Catalina, o otra cocinera, y que aquella noche le echó este que depone y el dicho Francisco tomaron el dicho indio que lo oían dar gemidos y que le echaron aceite por la boca, creyendo que había bebido agua de yuca ${ }^{3}$ y que así estuvo gimiendo toda aquella noche y otro día lo pasaron a otro bohío de indios para que lo curasen mejor y que después desde a dos o tres días que estaba sin habla se murió y lo echaron en una sabana en un hoyo que hicieron.

Fue preguntado, por el dicho señor alcalde mayor, si sabía de otro indio que el dicho Solís azotó que le habían traído los alguaciles del campo en su casa, dijo que no sabe más de oírlo decir a unos y a otros que iban a la estancia, que no se acuerda quien son.

Fue preguntado si el dicho Francisco de Solís ha mandado a este testigo que los días de fiesta trabajase con los indios, especialmente el día del Corpus Christi pasado. Dijo que no y que esta es la verdad y no sabe otra cosa. Firmolo de su nombre Marcos de Cáceres, Cristóbal de la Torre -f. 2 - escribano público.

En la villa de Santiago, a diez y nueve días del mes de octubre año del nacimiento de Nuestro Señor Jesucristo de mil y quinientos y nueve años, el noble y muy virtuoso señor el señor licenciado Marcos de Aguilar, alcalde mayor de estas islas y Tierra Firme del Mar Océano, descubiertas y por descubrir, por el Ilustre y muy Magnífico señor don Diego Colón Almirante, Virrey y Gobernador de ellas por sus Altezas, en presencia de mi Esteban de la Roca, escribano de su Juzgado y Audiencia, queriendo proseguir y prosiguiendo la pesquisa e información comenzada a hacer por el dicho licenciado Juan Carrillo, alcalde mayor, hizo parecer ante si al dicho Marcos Pérez de Cáceres y le hizo las preguntas siguientes:

Fue preguntado que mal cree él que traía el dicho indio Gasparico, dijo que traía calenturas. Fue preguntado como lo sabe, dijo que porque le atentó y vio que la tenía y que Cristóbal Valdovinos, que traía al dicho indio, le dijo a este testigo que le tomaba al dicho indio el enemigo por el camino y se le echaba, porque traía que lo hacía de roncero ${ }^{4}$ y no porque tuviese dicho mal.

3 En el texto aparecen algunos datos sobre ciertos tratamientos médicos utilizados en los primeros momentos de la colonización. Así, como vieron los españoles al indio agonizando, creyeron que había tomado hierbas para suicidarse y para intentar curarle le dieron a beber aceite utilizado, sin duda, como laxante. Sin embargo, los indios allí presentes creyeron que le habían proporcionado zumo de yuca, pues según parece por otros textos posteriores ellos lo utilizaban comúnmente como vomitivo. 
Fue preguntado si sabe que el dicho Solís estando presente al tiempo que el dicho Cristóbal Valdovinos traía el dicho indio y diciéndole el dicho Cristóbal de Valdovinos el mal que el dicho indio traía no obstante aquello le azotó $-f$. $2 v$ - luego. A la otra dijo este testigo que sabe y vio que el dicho Francisco de Solís azotó luego al dicho indio como dicho tiene en su primer dicho que dijo ante el licenciado Carrillo. Y fue preguntado que cuanto tiempo ha que vine ante el dicho Francisco de Solís, dijo que ha más de diez años que vine con él de Castilla y acá y que vino con él a estas partes y hoy día vive con él. Fue preguntado si quiere mal o bien al dicho Francisco de Solís, dijo que le quiere bien que es su Señor y que no le tiene mala voluntad ninguna. Marcos Pérez.

Y después de lo susodicho, sábado veinte días del mes de octubre se presentó este testigo que se sigue: Gonzalo de Niebla, criado de García de Paredes, vecino de esta villa de Santiago, testigo recibido jurado y preguntado. Y él fue preguntado cerca del caso dijo que lo que sabe es que un Valdovinos trajo al dicho indio, cuyo nombre este testigo no se acuerda, salvo que sabe que es aquel indio que después murió de suso contenido y que oyó decir al dicho Valdovinos que no le podía traer al dicho indio por el camino que le tomaría el diablo y que lo entregó al dicho Solís y que el dicho Solís dijo a este testigo luego como vino el dicho indio comenzó darle de azotes porque se acuerde de nosotros y que este testigo tomó un látigo y le dio en él media docena de azotes y que después que así lo hubo azotado este testigo el dicho Francisco de Solís dijo a Marcos que le metiese a la $-f$. 3 -cocina y le diese de cenar y que el dicho Marcos dio de cenar al dicho indio que después que cenó el dicho indio se quedó allí en la cocina a dormir aquella noche y que luego otro día siguiente casi a medio día el dicho indio se fue a su bohío, a donde estaban los otros indios, y que desde a cuatro o cinco días el dicho Marcos dio a beber al dicho indio un poco de aceite y que después de a unos tres o cuatro días después que el dicho indio bebió el dicho aceite vio muerto este testigo al dicho indio y vio sacar una azada para lo enterrar. Y que fue preguntado, por el dicho Señor alcalde mayor, que le había dicho que bebiese este testigo en este caso y dijo que viniendo este testigo con cierto maíz de la estancia del dicho su amo le dijo Francisco de Solís a este testigo Gonzalo de Niebla testigo que hiciste que has de ser testigo y ve allá al dicho alcalde mayor y dirás tu dicho y que esto que se lo dijo el dicho Francisco de Solís estando preso dentro en la cárcel pública de esta

4 Esta palabra viene de ronzal, que significa cuerda que se ata a la cabeza de una bestia de carga para sujetarla o conducirla. En sentido figurado, y como se puede observar a través de las declaraciones de otros testigos, significaría que el indio venía atado y sujeto. 
dicha villa, en presencia de los que allí estaban, el viernes que pasó día de San Lucas y que esto es lo que sabe de este hecho para el juramento que hizo y firmolo de su nombre Gonzalo...

Y luego, incontinenti, este dicho día el dicho señor alcalde mayor mandó parecer ante si al dicho Miguelico, indio del dicho Francisco de Solís de suso contenido, y siendo interprete jurado en forma de derecho Alonso de Rivera, natural de Rivera del maestrazgo de Santiago, vecino de esta villa de Santiago y para la declaración del dicho indio el dicho senor alcalde mayor dijo al dicho intérprete que le pregunte al dicho indio que es lo que sabe cerca de la muerte del dicho indio Francisquito de que de caso se hace mención y luego el dicho intérprete le preguntó cerca de ello y dijo que el dicho indio decía que en el tiempo de Valmaseda este indio se huyó y que después el dicho Cristóbal de Valdovinos, criado del dicho Francisco de Solís, fue al Maríen por este dicho indio y por otros que allá estaban huidos del dicho Francisco de Solís y que el dicho Cristóbal de aquel camino trajo de allá del Maríen este indio, Miguelico y al dicho Francisquito a la hacienda de Esperanza del dicho Francisco de Solís a donde al presente estaba el dicho Francisco y sus criados. Fue preguntado el dicho indio por el dicho intérprete si vio que el dicho Solís azotó o hizo azotar al dicho indio Francisquito las manos atadas alto a una tiranta que a mala pena llegaba las puntas de los pies al suelo. Dijo el dicho intérprete que el dicho indio Miguelico decía que vio que el dicho Solís hizo atar las manos altas al dicho Francisquito a la dicha tiranta y los pies que llegaban a $-f$. $5 v$-mala pena al suelo con un hizo y que Francisco Chocarrero, por mandado del dicho Solís, con un cordel de la cincha del caballo le dio obra de cuarenta azotes y que el dicho Solís tomo el azote de la mano al dicho Francisco Chocarrero y que le dio el mismo Solís otros muchos azotes diciéndole, a cada azote que le daba,"Axura Higuerito axura Señor" porque vos acordéis y que cuando el dicho Solís le comenzó a dar al dicho indio que ya el dicho indio tenía corriendo sangre las espaldas y que luego lo hizo desatar y lo envió al bohío del Capitán y que vio el dicho indio resistir aquel día y noche revesana? el dicho indio y que otro día siguiente enterraron al dicho indio junto ante el río. Item, le preguntó el dicho intérprete al dicho indio Miguelico que si cuando los tráa del Maríen el dicho Cristóbal de Valdovinos del Maríen(sic) si el dicho Francisquito venía sano o doliente, dijo el dicho intérprete que decía el dicho indio que el dicho Francisquito siempre vino sano y bueno por el camino y comiendo y viniendo como sano. Item, le preguntó el dicho intérprete al dicho indio si sabe que el dicho indio murió de los dichos azotes. Dijo el dicho intérprete que decía el dicho indio Miguelico 
que el dicho Francisquito murió de los azotes a lo que él cree porque venía sano y bueno y comía y bebía bien salvo que desde que le dio los dichos azotes que nunca más comió hasta que murió y que el dicho intérprete dijo que esto era lo que el dicho Miguelico declaraba y declaró so cargo del juramento que hizo. Fue preguntado a dicho intérprete si tiene o dio -f. 6-mala voluntad al dicho Francisco de Solís o si fue avisado, sobornado y para que deba hacer sin esta relación en la declaración del dicho indio, dijo que no y que quería que venciese esta causa el que tuviere mejor justicia y trajere la verdad y firmolo de su nombre Alonso de Rivera...

Por los artículos y preguntas siguientes sean preguntados los testigos que son y serán preguntados por parte de Francisco de Solís en el pleito que ha y trata con la justicia real para en prueba de las tachas y objetos que el dicho Francisco de Solís tiene puestas contra los testigos por parte de la justicia contra él presentados cerca de la muerte de los indios de que es acusado, son las siguientes:

1.-Primeramente, sean preguntados si conocen al dicho Francisco de Solís y de que tiempo.

2.-Item, si conocen a Cristóbal de Valdovinos a Marcos Pérez -f. 28- y a Gonzalo de Niebla y a Francisco de Burgos Chocarrero y Alonso de Rivera, lengua, y a Mencía, esclava de Gonzalo de Villegas, y a Catalina y a Sebastianico y Escobar y Miguelico, naborías del dicho Francisco de Solís, indios testigos todos presentados por parte de la justicia real contra el dicho Francisco de Solís y de que tiempo acá.

3.--Item, sean preguntados si saben, creen, vieron u oyeron decir el dicho de Cristóbal de Valdovinos, testigo presentado contra el dicho Francisco de Solís antes y al tiempo que dijese su dicho en esta causa era y es hombre pobre y vil y de muy poco seso y juicio muy liviano en sus hechos y que de ligero se cree y desdice en poco rato y tal que según quien es es de presumir de él que quien quiera le hará decir lo que no es sobre que por poca dádiva o precio, señal o miedo se puede sobornar, y por tal es habido y tenido y comunmente reputado.

4.- Item, si saben y creen que Francisco Chocarrero nunca fue criado ni asoldado del dicho Francisco de Solís y nunca venir con él en esta isla ni en Castilla y si alguna y si alguna (sic) fue a la estancia del dicho Francisco de Solís sería como era truhán se iría a holgar allá y no porque era su mozo.

5.-Item, si saben Marcos Pérez y Gonzalo de Niebla testigos presentados por parte de la justicia al dicho tiempo que dijeron sus dichos 
ser perjuros y haberse perjurado por ello fueron acusados criminalmente y el Gonzalo de Niebla fue sentenciado criminalmente azotes por ello la cual sentencia $-f$. $28 v-$ se ejecutó en él públicamente en la villa de Santiago y el otro por ausentarse no se ha seguido contra él los cuales por tales son habidos y tenidos.

6.- Item, si saben y creen que el dicho Francisco de Burgos ser Chocarrero al dicho tiempo ser hombre pobre y vil y de poca opinión y truhán y chocarrero y por tal le pusieron el nombre de Chocarrero y que andaba diciendo truhanerías por las calles echando sus vergüenzas de fuera y otras vilezas que a ninguna persona de honra sería bien atribuido y por tal es tenido comúnmente y reputado.

7.- Item, si saben el dicho Alonso de Rivera intérprete ser hombre parlero y de poca opinión y crédito y allende de ser hombre senil y pobre y tal que según su trato y conversación no se le debe dar ningún crédito en causa alguna, cuanto más en esta que es criminal y por tal es habido y comúnmente reputado.

8.- Item, si saben y creen que todos los indios generalmente son hombres de poca conciencia que no temen a Dios ni cumplen sus mandamientos, ni saben que daño se recrece de jurar falso y no decir verdad a sus conciencias testimoniaron de si mismos y mecidos agoreros no cristianos cualquier mal a la gente de Castilla porque le hacen servir en sus haciendas y por poco que le castiguen toman enemistad y otras muchas tachas los cuales testigos declaren que tantas y cuantas saben aquellos y en poco temor y dádiva dicen lo - $f$. $29-$ que es y lo que no es por tales son habidos y tenidos comúnmente reputados.

9.-Item, si saben Mencía y Estebanico, Escobar, Catalina, Miguelico naborías del dicho Francisco de Solís ser indios e indias, especialmente Mencía, y allende de ser india es esclava de Gonzalo de Villegas personas que siendo indias caben en ellas las sobre dichas tachas de los indios y tal es de presumir y creer.

10.--Item, si saben que el dicho Francisco de Solís no es de presumir según quien él es y según su venir y manera y según ha sido y es servidor de Sus Altezas y de su justicia haber querido castigar a ningún indio ni castigarlo con ánimo de matar ni haber excedido castigo en ellos más de lo permitido en tal posiciones ha sido y tenido y comúnmente reputado siendo como es hidalgo.

11.- Item, si saben que todo lo susodicho y cada cosa y parte de ello es público y notorio en esta isla en la mayor parte de ella entre las personas que de ello en noticia y conocimiento y seanles hechas a los dichos testigos del oficio de Vuestra Merced todas las otras preguntas al caso pertenecientes al cual para ello imploro. 
El dicho Gonzalo de Villegas testigo jurado en este caso dijo lo siguiente:

1.-A la primera pregunta dijo que conoce al dicho Francisco de Solís de dos años a esta parte poco más o menos.

2.-A la segunda pregunta dijo que conoce a los $-f$. $29 v-$ contenidos en la dicha pregunta de dos años a esta parte cada uno en su tiempo.

3.-A la tercera pregunta dijo que este testigo conoce al dicho Cristóbal de Valdovinos y que sabe que cabe en él todas las tachas contenidas en la dicha pregunta y por tal este testigo lo tiene y es habido y tenido entre quien lo conoce.

4.- A la cuarta pregunta dijo que sabe que el dicho Francisco Chocarrero no lleva soldada con el dicho Francisco de Solís más de cuanto se iba a casa y a su estancia por ser chocarrero le daban alguna joya y que esto que lo sabe porque este testigo estaba con el dicho Solís en una posada todos juntos y lo supiese si viniese con él por que lo viere.

5.-A la quinta pregunta dijo que sabe lo contenido en la dicha pregunta porque estaba este testigo presente al tiempo que los acusaron y que sabe que le dieron sentencia a darle cien azotes y que le fue dados por esta villa y que al dicho Marcos Pérez sino se soltara como se soltó cree este testigo cree (sic) que también le dieran otros tantos azotes porque trayéndolo de la Buenaventura para esta villa se fue y que esto sabe de esta pregunta.

6.-A la sexta pregunta dijo que sabe lo contenido en la dicha pregunta porque sino le daban de comer no tenía de que comer y que todo lo otro contenido en la pregunta sabe porque lo veía muchas veces.

7.-A la séptima pregunta dijo que sabe que el dicho - $f$. 30-Alonso de Rivera es pobre hombre de baja suerte y que ha oído a muchos que es hablador congraciándose muchas veces y que por esto este testigo cree que en tal caso como este no se le debe dar crédito.

8.-A la octava pregunta dijo que sabe lo contenido en la dicha pregunta porque es notorio y que así mismo lo sabe porque si les castigan algún cristiano luego le quieren mal.

9.-A la novena pregunta dijo que este testigo dice lo que dicho ha en la pregunta antes de esta y que por tales este testigos los tiene y que aunque les haga mucho bien sino están contentos luego se quejan y se les mandan muchas veces el propósito que tiene que esto es notorio.

10.-A la décima pregunta dijo que este testigo por tal lo tiene como la pregunta lo dice porque sabe su condición y que sabe que cuando era justicia ni tenía algún indio para castigar no le daba la pena que merecían y esto sabe porque así lo veía y que sabe que el dicho Escobar le 
quería muy mal porque el dicho Francisco de Solís lo había hecho azotar porque tomó un cuchillo para matar un cristiano y que cree que por esto cualquier cosa diría contra el dicho Francisco de Solís.

11.-A la once pregunta dice lo que dicho ha y en ello se afirma y firmolo de su nombre Gonzalo de Villegas.

Y el dicho Juan de Aguirre testigo jurado en esta razón habiendo jurado según derecho dijo lo siguiente:

1.-A la primera pregunta dijo que conoce al dicho Francisco de Solís de dos años a esta parte.

2.-A la segunda pregunta dijo que conocía a Valdovinos y - f. 30va Francisco de Burgos y Alonso de Rivera y todos los otros contenidos en la pregunta excepto al dicho Miguelico.

3.-A la tercera pregunta dijo que dice y sabe lo contenido en la dicha pregunta porque todo sabe en él como la pregunta dice y porque este testigo por tal le conoce porque no sabe si daría el contrario de la verdad o si se perjuraría.

4.-A la cuarta pregunta dijo este testigo no cree que venía con el dicho Solís el dicho Francisco porque no era hombre para venir con nadie sino donde le daban de comer ahí se allegaba y que sabe que estaba algunos días en casa del dicho Solís pero no porque viviese con él.

5.-A la quinta pregunta dijo que vio azotar al dicho Gonzalo de Niebla pero que no sabe otra cosa.

6.-A la sexta pregunta dijo que este testigo le conoció por hombre Chocarrero y de baja suerte pero que lo demás que no sabe.

7.-A la séptima pregunta dijo que este testigo lo tiene por tal como la pregunta lo dice al dicho Rivera y le conocía y que es muy pobre y que este testigo no lo presentaría por testigo ni caso que a él le fuese algo por que no tendría su dicho en nada.

8.-A la octava pregunta dijo que es verdad todo lo contenido en la dicha pregunta porque así es notorio y por tal este testigo tiene y tienen muchas tachas allende de las contenidas en esta partes que son largas de decir.

9.-A la novena pregunta dijo que dice lo que dicho ha en $-f .3 I-$ la primera pregunta antes de esta.

10.-A la décima pregunta dijo que este testigo por tal lo tiene como la pregunta lo dice y que no cree que el no cree (sic) que habrá cosa que no debiese en lo que le piden porque se conoce por buen hombre.

11.-A la once pregunta dice que dijo lo que dicho ha en ello se afirma y no lo firmó de su nombre porque no sabía. 
El dicho Rodrigo Manzorro testigo jurado en forma dijo lo siguiente:

1.-A la primera pregunta dijo que conoce al dicho Francisco de Solís de año y medio a esta parte.

2.-A la segunda pregunta dijo que conoce a Valdovinos y a Francisco de Burgos y Alonso de Rivera y a la dicha Mencía y que los demás contenidos en la pregunta que los no conoce.

3.-A la tercera pregunta dijo que es hombre de poco saber y mudable y simple y lo demás que lo no sabe y que lo sabe lo que dicho ha porque ha visto decir una cosa y luego decir otra y por tal habido y tenido.

4.-A la cuarta pregunta dijo que nunca este testigo oyó decir ni vio en esta isla vivir con el dicho Francisco de Solís porque en Castilla no lo sabe.

5.-A la quinta pregunta dijo que la no sabe porque no los conoce.

6.-A la sexta pregunta dijo que la sabe porque así lo ha visto porque tal es la pública voz y fama pero que nunca le vio echar sus vergüenzas de fuera.

7.-A la séptima pregunta dijo que la sabe que es hombre - f. $3 / v-$ mentiroso y trampón y que lo sabe porque por tal es habido y habido en la villa de Santiago.

8.-A la octava pregunta dijo que sabe que son personas de muy poco juicio y saber y que no saben que cosa es conciencia ni jurar y que quieren mal a los cristianos y aun a quien los trata bien, la mayor parte de ellos.

9.-A la novena pregunta dijo lo que dicho ha.

10.-A la décima pregunta dijo que la cree porque este testigo le tiene por hombre de seso e hidalgo y cree que no le daría con pensamiento de matarlo.

11.-A la once pregunta dijo que dice lo que dicho ha y en ellos se afirma y firmolo de su nombre Rodrigo Manzorro.

El dicho Juan Carrillo Mexía testigo jurado en forma dijo lo siguiente:

1.-A la primera pregunta, dijo que conocí al dicho Francisco de Solís de año y medio a esta parte y así mismo a Francisco Chocarrero conoce.

2.-A la segunda pregunta, dijo que no conoce a los contenidos en la dicha pregunta más de al dicho Valdovinos y Alonso de Rivera.

3.-A la tercera pregunta dijo que este testigo que no sabe si es pobre pero que sabe que lo tiene por hombre liviano y Chocarrero y es hombre asoldadado que solía venir con el dicho Francisco de Solís y este testigo lo tiene por hombre liviano y que este testigo no lo preguntaría en 
cosa que le tocase por testigo porque pensaría que sería ruin y $-f$. 32 liviano en lo que jurase porque según a este testigo le parece sabe muy poco.

4.-A la cuarta pregunta dijo este testigo cree que no vivió con él porque no le conoció más de cuanto sabe que es chocarrero y por tal es público en esta isla y truhán.

5.-A la quinta pregunta dijo que no la sabe.

6.-A la sexta pregunta dijo que este testigo que por tal le conoció otro oficio sino el susodicho de truhán y de aquel le veía venir y que lo demás que no la sabe.

7.-A la séptima pregunta dijo que sabe que es hombre pobre pero que lo demás lo non sabe.

8.-A la octava pregunta dijo que sabe que son personas de poco juicio y entendimiento y mal acondicionados y que lo sabe porque es notorio y que usen mal a los cristianos generalmente aunque les hacen bien.

9.-A la novena pregunta dijo que la non sabe porque no los conoce.

10.- A la décima pregunta dijo que cree este testigo que el dicho Francisco de Solís según su persona y manera no castigaría a ningún indio con voluntad dañada de matarle salvo azotarle si lo merecía y que este testigo no lo tiene en tal posición que haría lo susodicho.

11.-A las once preguntas dijo lo que dicho ha y en ello se afirma y firmolo de su nombre Juan Carrillo.

El dicho Miguel de la Casa testigo presentado por el $-f .32 v-$ dicho Francisco de Solís habiendo jurado en forma:

1.-A la primera pregunta dijo que conoce al dicho Francisco de Solís de dos años a esta parte.

2.-A la segunda pregunta dijo que conoce a Valdovinos y al Chocarrero y Alonso de Rivera y a Mencía que los otros conocen aunque los había visto algunas veces los cuales conoce de cinco años y de dos años y de un año a esta parte.

3.-A la tercera pregunta, dijo que el dicho Valdovinos es hombre de poca manera y hombre que vive de soldada y que todos lo tienen por hombre no muy atento y que cree este testigo que no es hombre que tiene juicio natural preguntado porque lo cree dijo que ha visto en juicio demandar al dicho Valdovinos un curador que procurase por él y que lo demás no lo sabe.

4.-A la cuarta pregunta dijo que no oyó decir que dicho Chocarrero viviese con el dicho Solís más de cuanto algunas veces le vio comer en su casa como hacía en casa de este testigo y de los otros. 
5.-A la quinta pregunta dijo que no sabe lo susodicho se perjuraron más de cuanto vio este testigo que uno de estos dos y otro fueron sentenciados azotes y vio este testigo azotar uno de ellos pero que no sabe como se llama y que por tal lo tiene este testigo ante él azotado.

6.-A la sexta pregunta dijo que lo que de ella sabe es que muchas veces vio que el dicho Francisco de Burgos decía - $f$. 33-chocarrerías en Santiago y aullaba como lobo y ladraba como perro y hacía otros autos de tacha y Chocarrero y que lo demás que no lo sabe.

7.-A la séptima pregunta dijo que conoce al dicho Alonso de $\mathrm{Ri}$ vera y que lo tiene por hombre pobre y de baja manera y hombre mentiroso que miente más que habla porque no es hombre autorizado ni tal que cumple a hombre de honra y este testigo y en la dicha villa por tal es tenido según público y notorio y lo demás que no lo sabe.

8.-A la octava pregunta dijo este testigo que tiene por hombres de poca consciencia y que ni temen a Dios ni saben que cosa es ni en que se perjuran o dañan sus conciencias, preguntado porque los tiene por tales dijo que porque algunas veces a oído decir a indios que creen en cemíes y que no quieren ser cristianos ni saben que son los mandamientos y que este testigo ninguna cosa creía de ellos diciendo juramento ni aun sin él porque algunas veces los ha visto contradecirse y no saber si se contradicen ni si no.

9.-A la novena pregunta dijo que dice que lo que dicho tiene en la primera pregunta antes de esta y en ella se afirma y dice en esta pregunta lo que en la de arriba.

10.-A la décima pregunta dijo que algunas veces ha visto que el dicho Francisco de Solís siendo alcalde azotaba algunos indios como juez ${ }^{5}$ y que nunca le vio hacer cosa demasiada ni cree este testigo que su intención fue de matar $-f$. 33v-ningún indio ni lo mató, preguntado por qué lo cree dijo porque en tanto tiempo que ha que conoce al dicho Francisco de Solís y le tiene en buena reputación y por hombre de conciencia y por tal es habido y tenido cerca de las personas que con él han tratado.

11.-A la duodécima pregunta dijo que dice lo que dicho tiene y que así es pública voz y fama y esta es la verdad so cargo del juramento que hizo y firmolo de su nombre Miguel de la Casa.

5 Como bien se dice en el pleito, el alcalde ordinario era "juez" en primera instancia en todos los casos de indios, no apareciendo en ningún momento la figura del visitador, que pese a estar legislado ya en la época de frey Nicolás de Ovando que hubiese dos por villa, no parece que se llegasen a establecer realmente. 
El dicho Pero Hernández herrador testigo presentado por el dicho Francisco de Solís jurado en forma:

1.- A la primera pregunta dijo que conoce al dicho Francisco de Solís de un año y medio a esta parte.

2.-A la segunda pregunta dijo que no la sabe ni conoce a lo en ella contenidos y cerca al dicho Francisco de Burgos que lo conoce de un año a esta parte.

3.-A la tercera pregunta dijo que no la sabe.

4.- A la cuarta pregunta dijo que no la sabe

5.-A la quinta pregunta dijo que no la sabe.

6.-A la sexta pregunta dijo que no embargante que arriba dice que no conoce a los en la segunda pregunta contenidos dijo conoce al dicho Francisco de Burgos Chocarrero y que sabe que es chocarrero y desvergonzado y hombre - f. 34-senil, preguntado como la sabe dijo que porque este testigo le vio muchas veces decir chocarrerías y tirar pedos y aun en la boda de Tostado echó sus vergüenzas de fuera este testigo se las vio y otras muchas cosas que no son de hombre de pro y por tal es habido y tenido.

7.-A la séptima pregunta dijo que no la sabe.

8.-A la octava pregunta dijo que cree todo lo que en la dicha pregunta se contiene, preguntado que por qué lo cree dijo que porque algunas veces en casa del Comendador Mayor ha habido Alonso de Cáceres, "indio, que es lengua bien entendido estar borracho con hierbas y otros muchos indios decir mentiras y que claro está que quieren mal a las cristianos y que los querrían ver muertos porque los castigan y apremian lo cual es así público y notorio en esta isla.

9.-A la novena pregunta dijo que no conoce las dichas indias pero que bien cree que las dichas tachas caben en ellos y por lo que dicho tiene y por otras muchas cosas que les ha visto hacer a los indios en esta Isla.

10.-A la décima pregunta, dijo que cree este testigo que el dicho Francisco de Solís no castigaría a ningún indio por lo matar ni herir demasiado, preguntado por qué lo cree dijo que porque este testigo tiene por hombre hidalgo al dicho Francisco de Solís y de buena conciencia a ningún indio que el castigase cree haberle hecho cosa alguna porque le quisiese matar ni vengarse de él ni menos así de decir que - $f$. $34 v$-hiciese castigo no debido a los indios cuando fue alcalde salvo ahora y que ésto

6 El Alonso de Cáceres que aparece en el texto es sin duda el mismo al que alude el Interrogatorio de los Jerónimos, fue puesto en libertad junto al cacique Diego Colón para "experimentar" su capacidad. Pese a su carácter ladino se seguía "emborrachando con hierbas", es decir, haciendo sus cohobas y areytos como lo había hecho siempre. 
es así pública voz y fama y la verdad so cargo del juramento y no sabe escribir.

El dicho Pedro Benítez, testigo presentado por el dicho Francisco de Solís habiendo jurado:

1.-A la primera pregunta dijo que conoce al dicho Francisco de Solís de dos años a esta parte.

2.-A la segunda pregunta dijo que no conoce a los en ella contenidos excepto al dicho Francisco de Burgos que lo conoce de un año a esta parte y que algunos indios del dicho Francisco de Solís pero que no se acuerda de estos.

3.-A la tercera pregunta dijo que no la sabe.

4.- A la cuarta pregunta dijo que nunca vio al dicho Francisco de Burgos venir con el dicho Francisco de Solís ni tal ni más de cuanto algunas veces comía en su casa como otros.

5.-A la quinta pregunta dijo que no la sabe.

6.-A la sexta pregunta que este testigo tuvo todo el dicho tiempo al dicho Francisco Chocarrero por hombre pobre, vil y truhán, preguntado por qué lo tuvo por tal dijo que porque le vio andar en esta villa diciendo truhanerías y chocarrerías y lo de más que no lo sabe.

7.-A la séptima pregunta dijo que no la sabe.

8.-A la octava pregunta dijo que este testigo tiene por - $f$. 35 -hombres de poca conciencia a los indios y que no temen a Dios ni lo conocen ni creen en él, preguntado por qué lo cree y lo tiene así dijo que allende de muchas cosas que de ellos ha visto y ha sido en Xaragua fue una india casada a decir al Comendador Mayor que su marido se echaba con otra su hermana y que la hermana lo fue a decir y dijo que se había echado el marido de su hermana con ella y que el Comendador Mayor se informó de la verdad y halló que era mentira que lo habían hecho porque les habían dicho que quien dormía con dos hermanas lo habían de quemar ${ }^{7}$ y que sabe que

7 Esta orden impuesta por el gobernador Ovando apunta, quizá, hacia una poligamia entre los indios mayor de lo que se había sospechado hasta ahora, pues historiadores como Roberto Cassá, basándose en textos de cronistas, defendían que ésta tan sólo fue frecuente entre caciques y principales, Cassa, pág. 145. Sin embargo, este supuesto ordenamiento de Ovando debió surtir poco efecto pues todavía en 1517 el licenciado Vázquez de Ayllón, en un memorial dirigido a los Jerónimos proponía que se castigase a todos los indios "que se echaren, de cualquier nación que sea, con madre e hija o con dos hermanas o parientas...". AGI, Indiferente General 1624, r. 1, fol. 51v. También en Giménez Fernandez, Manuel: El plan Cisneros-Las Casas para la reformación de las Indias, t. I, Madrid, 1984, páginas 573-596. 
quieren mal a los cristianos y porque este testigo lo ha visto decir a muchos indios que son bellacos los cristianos.

9.-A la novena pregunta dijo lo que dicho tiene y así lo cree de todos los indios.

10.- A la décima pregunta dijo que cree este testigo que el dicho Francisco de Solís no castigaría ningún indio con intención de lo matar ni mataría, preguntado por qué lo cree dijo porque le conoce que es hidalgo y le tiene por hombre de buena conciencia y tal que no querría matar a nadie no haciendo cosa por que lo cual no le harían los indios.

11.-A la oncena pregunta dijo que así es pública voz y fama y esta es la verdad so cargo de justicia que hizo prometer...

$Y$ luego el dicho señor alcalde mayor en nombre de la justicia real dijo que concluía y concluyó y así firmaba y asignó término para dar cualquier sentencia para luego y $-f$. 38 - dende en adelante para de cada día que forrado no sea.

En este proceso de pleito que es entre partes de la una la justicia real en sentencia y de la otra reo defendiente Francisco de Solís el cual dicho pleito se cursó sobre razón de ciertos indios que el dicho Francisco de Solís fue acusado diciendo que los mató y visto la cabeza de proceso que contra él fue hecha y las excepciones y defunciones que por parte del dicho Francisco de Solís contra él la fueron alegadas y vistas las probanzas presentadas por parte de la dicha justicia Real y las probanzas hechas por el dicho Francisco de Solís y vistas las dichas alegaciones y la probanza sobre ellas hecha por parte del dicho Francisco de Solís visto todo lo demás que se debió ver juntándolo con la disposición del derecho a que me refiero falló que debo absolver y absuelvo al dicho Francisco de Solís de la cabeza de proceso contra él hecha sobre la muerte de los dichos indios porque no embargante que la justicia real hizo probanza sobre la dicha -f. 38v-cabeza de proceso el dicho Francisco de Solís alegó y probó excepciones y defensiones y objetos contra la dicha cabeza de proceso tales y en tal manera que excluyen y eliden la dicha cabeza de proceso contra él hecha para por algunas causas que de ello me mueven y de lo procesado resulta mandó que el dicho Francisco de Solís por esta razón salga sentenciado de la villa de Santiago y que no entre en ella sin mi licencia y mando so pena de un marco de oro para la cámara y fisco de sus Altezas en la cual dicha pena desde ahora le he por condenado lo contrario haciendo y por causa que a ello me mueven no hago condenación de costas salvo que cada una de las partes separe a las que hizo y por esta mi sentencia definitiva juzgando así lo pronuncio y mando en estos escritos y por él los del licenciado Aguilar. 
Y dada y pronunciada fue esta sentencia por el dicho señor alcalde mayor en ausencia de las partes en miércoles - f. 39-nona catorce días del mes de agosto año del Señor de mil y quinientos y diez años...

Yo Esteban de la Roca escribano público de esta dicha villa de Santo Domingo que de la audiencia y juzgado del dicho señor licenciado Marcos de Aguilar alcalde mayor y juez susodicho en todo lo que dicho es que ante el dicho señor alcalde mayor pasó por entero este presente proceso hice escribir según que ante mi pasó e hice en él este mío signo a tal en testimonio de verdad.

Esteban de la Roca

Escribano público 